\title{
Understanding Social Risk Variation Across Reintegration of Post-Ischemic Stroke Patients
}

\author{
Katryna Cisek ${ }^{1} \bullet$ Thi Nguyet Que Nguyen ${ }^{1} \bullet$ Alejandro Garcia-Rudolph ${ }^{2} \bullet$ \\ Joan Saurí $\bullet$ John D. Kelleher ${ }^{1,3}$ \\ ${ }^{1}$ PRECISE4Q, Predictive Modelling in Stroke, Information Communications and \\ Entertainment Institute, Technological University Dublin, Dublin, Ireland; ${ }^{2}$ Department of \\ Research and Innovation, Institut Guttmann, Institut Universitari de Neurorehabilitació \\ Adscrit a la UAB, Badalona, Spain; ${ }^{3}$ ADAPT Research Centre, Technological University \\ Dublin, Ireland
}

Author for correspondence: Katryna Cisek, PRECISE4Q Predictive Modelling in Stroke, Technological University Dublin, Ireland. E-mail: katryna.cisek@tudublin.ie

Cite this chapter as: Cisek K, Nguyen TNQ, Garcia-Rudolph A, Saurí J, Kelleher JD.

Understanding Social Risk Variation Across Reintegration of Post-Ischemic Stroke Patients.

Pluta R, editor. Cerebral Ischemia. Brisbane (AU): Exon Publications; 2021. Online first Oct 5.

Doi: https://doi.org/10.36255/exonpublications.cerebralischemia.2021.reintegration

\begin{abstract}
The quality of life of post-ischemic stroke patients during reintegration is affected by a range of factors, including the risk of insufficient social and family support, as well as socio-economic status. A patient who is unable to access needed social support, such as home health care or a day center, is at a greater risk of poorer quality of life during reintegration. Consequently, the key goals of poststroke reintegration are to improve patient outcomes across these factors, to inform reintegration decisions, as well as design personalized interventions for patients with social risk. This chapter presents a case-study of 240 patients of the Catalonia region of Spain that uses data visualization techniques (known as Sankey diagrams) to provide insight into changes in quality of life risk factors
\end{abstract}

In: Cerebral Ischemia. Pluta R (Editor). Exon Publications, Brisbane, Australia. ISBN: 978-0-6450017-9-2; Doi: https://doi.org/10.36255/exonpublications. cerebralischemia.2021

Copyright: The Authors.

License: This open access article is licenced under Creative Commons Attribution-NonCommercial 4.0 International (CC BY-NC 4.0) https://creativecommons.org/licenses/by-nc/4.0/ 
such as gender, and stroke severity, during reintegration. As supported by the case-study, social risk is a complex and multifactorial phenomenon that can vary significantly for an individual over the course of stroke rehabilitation and reintegration.

Keywords: ischemic stroke; quality of life; reintegration; Sankey diagram; social risk

\section{INTRODUCTION}

Worldwide, more than 11 million ischemic strokes occur annually, and an estimated $10-20 \%$ of these events occur in young people aged 18 to 50 years (1). Moreover, the incidence of ischemic stroke has risen in the younger population aged under 55 years old, especially in the United States (2) and in Europe (3). Therefore, the factors that drive successful reintegration post-stroke are of growing importance because of the changing demographics of patients, and the unique clinical challenges and needs of younger patients. However, as the incidence of ischemic stroke increases with age, associations between factors for ischemic stroke and clinical outcomes have been primarily investigated in older patients, rather than the younger population (4). Moreover, social risks and barriers to successful reintegration have poorly understood complex demographic and cultural underpinnings, and are critical for informing clinical or social interventions (5).

Gender bias is an important consideration for reintegration, as across the globe, access to stroke care seems to be more difficult for women than men. Literature on the subject has already indicated that women after stroke tend to receive less specialized rehabilitation than men and are more likely to be referred to nursing homes (6). In a European Concerted Action involving 7 countries, including Spain ( $\mathrm{n}=4499)$, gender, but not stroke severity, was reported to be a major discriminating factor for the use of diagnostic resources or therapeutic interventions, such as carotid surgery. In spite of more severe clinical conditions, procedures such as brain imaging, Doppler sonography, echocardiogram, and angiography were performed significantly less often in women (7). Key treatments such as intravenous thrombolysis are less likely to be offered to older women than to members of other demographics; despite the fact that evidence indicates that older women benefit from thrombolysis as much as older men, women are more likely to be excluded from thrombolysis treatment (38\%) than men (19\%) if they are over 80 years of age (8), thus potentially impacting women's post-stroke quality of life and reintegration.

Stroke reintegration may involve years-long processes as patients adapt to their post-stroke conditions and disabilities, as they try to reintegrate back to their daily life, workplace and society (9), and this is especially true for younger stroke sufferers (10). Moreover, incidence of long-term complications and disabilities can strike up to half of all stroke survivors (11), and they may live with the consequences of stroke for over twenty years (12). Therefore, stroke in young adults has major social and economic impacts as it disables individuals in the peak of their most productive years $(13,14)$. These considerations emphasize the importance 
of the quality of life, social well-being, as well as unmet clinical needs and adequate support of patients during long-term reintegration (15).

Reintegration can be formally defined as the long-term outcome post-stroke that generally encompasses the home, community, and workplace or productivity activities $(16,17)$. The measure of the patients' reintegration into their family, communities and workplace includes concepts such as resilience and fragility. Resilience is the ability of the patient to deal with the adverse consequences of a stroke and maintain high life satisfaction despite challenges, including selfmotivation, initiative, and compliance during rehabilitation (18, 19). Fragility is the likelihood of a patient to retreat from life, socially isolate, suffer from poor life satisfaction, low self-esteem, and depression (20). Moreover, studies have identified several other important social factors impacting reintegration, such as environmental, socio-economic, as well as family and social support (21-24).

Owing to the spatiotemporal complexity of reintegration (occurring in the home, community, and workplace over long periods of time), there are several reintegration unmet patient needs, mainly personalized reintegration strategies and interventions that would support patients at risk of fragility. Timely implementation of the proper patient supports and interventions is hampered by a lack of understanding of factors contributing to patients' social risk and well-being and the impact of patients' socio-economic situations that would aid in identifying patient trajectories (resilience vs. fragility). Although there are several frameworks and conceptualizations of the multidimensional nature of reintegration $(25,26)$, further analysis integrating all of these factors is needed to fully explore the landscape of social risks and barriers and implement robust solutions to support patients unique needs and challenges during reintegration.

\section{EVALUATING REINTEGRATION}

As reintegration can involve a series of complex processes depending on the age, gender, stroke severity, the patient's cognitive, physical, and sensory perception status, and other socio-economic factors that contribute to the patients' functioning in their everyday life, there are various instruments and assessments for evaluating stroke reintegration.

\section{Comprehensive reintegration assessments}

Some of the widely used assessments include the Community Integration Questionnaire, the Reintegration to Normal Living Index, and European Quality of Life Five Dimension (EQ-5D). The Community Integration Questionnaire assessment is intended as a brief, reliable measure of an individual's level of integration into the home and community, as well as the workplace or returning to productivity, following traumatic brain injury (27). The Reintegration to Normal Living Index assesses mobility, self-care, daily activity, recreational activity, and family roles, to gauge "reorganization of physical, psychological, and social characteristics of an individual into a harmonious whole so that one can resume welladjusted living after incapacitating illness or trauma" (17). EQ-5D is possibly the most widely used generic health status questionnaire measuring quality of life on 
a 5-component scale including mobility, self-care, usual activities, pain/discomfort, and anxiety/depression; it has been proposed as a measure of a patient's quality of life profile, as well as providing a single index value for general health (28). However, although these instruments assess multiple dimensions of patients' reintegration, they tend to neglect the social model of disability, which is critical to improving patients' quality of life during reintegration (22, 29-31).

\section{Disability as a social model}

The traditional medical model views disability as a problem of the individual, directly caused by disease, trauma, or other health condition, which requires medical care provided in the form of individual treatment by professionals. Management of the disability is aimed at providing a cure or the individual's adjustment and behavioral change. Medical care is viewed as the main issue (32). On the other hand, the social model of disability sees disability as mainly a socially created problem, and basically as a matter of the full integration of individuals into society. Disability is not an attribute of an individual, but rather a complex collection of conditions, many of which are created by the social environment. Hence, the management of the problem requires social action, and it is the collective responsibility of society at large to make the environmental modifications necessary for the full participation of people with disabilities in all areas of social life. The issue is therefore an attitudinal or ideological one requiring social change, which at the political level becomes a question of human rights (33).

\section{Dimensions of social risk}

The United Nations Convention for the Rights of Persons with Disabilities (34), mandatory in the member states since its entry in 2008, recognizes the right to adequate housing (article 28) and to living independently and being included in the community (article 19). However, the reality of people with disabilities in most countries, for example Spain, is still far from matching this requirement and there are many institutionalized people or living in homes not adequate to their needs. Currently, in Spain, more than 1.8 million people with reduced mobility require help from third parties to leave the home and around 100,000 people, who do not have this help, never leave home (35).

In most countries, family support is critical, as family members are often the primary source of care for people with disabilities and people with chronic health conditions. The provision of family support is associated with positive family outcomes, specifically better family quality of life, functioning, satisfaction, and a reduction in stress (36). People with functional limitations or bodily impairments are generally disadvantaged in their opportunities to participate in social life. These restrictions not only contradict basic human rights (35), but frequently also affect people's health and well-being. There is consistent evidence that continued favorable exchange with one's proximate social environment (e.g., family, friends and work life) exerts beneficial effects on health and well-being (37). Conversely, social isolation or lack of close social ties is associated with poor health and increased mortality risk (38). These associations hold true for the general population worldwide but are particularly relevant for persons with physical disabilities, due to their restricted social participation (39). 


\section{CASE STUDY OF SOCIAL RISK UTILIZING VISUALIZATIONS}

Although reintegration encompasses a plethora of psychosocial, cognitive, physi$\mathrm{cal}$, and demographic factors, the case-study below focuses on the social model of disability utilizing a specialized social risk assessment with five dimensions of social risk. The goal of the case-study is to explore those social risk dimensions, as well as certain risk factors (gender, age, education, civil status, stroke severity, length of stay at the hospital, motor functional independence, and disability) in a 240-patient cohort of the Catalonia region of Spain, consisting of mostly male, young ischemic stroke patients utilizing Sankey diagram visualizations.

\section{Specialized social risk assessment}

To assess social risk of patients considering the above-mentioned factors, a social risk assessment was developed at the Institut Guttmann, called "Escala de Valoracion Socio Familiar" (EVSF). The assessment is based on the Gijon sociofamiliar scale that includes five items (housing, family situation, economic situation, relationships, and social support). Accordingly, the EVSF assessment consists of five items or dimensions: cohabitation, economic status (indicating income sufficiency), home status (indicating home accessibility in case of mobility problems), family support and social support (Table 1). Each of these five items has five levels of risk that are scored from 1 to 5. A higher score for each item represents higher risk in the social reintegration of the patient. The total score is the sum of the five items scores and is between 5 and 25 and determines four social risk categories: (i) no social risk (5 points); (ii) mild social risk (6-9 points); (iii) important social risk (10-14 points); and (iv) severe social risk ( $\geq 15$ points). Its reliability and validity were evaluated by contrasting the score obtained on the scale with a reference criterion of an independent, blind assessment by social work experts. It was reported to enable detection of risk situations and social problems with good reliability and acceptable validity (40).

\section{Patient population cohort criteria}

Demographic, diagnostic and assessment data utilizing the EVSF questionnaire during the rehabilitation and reintegration of patients were recorded and collected at the Institut Guttmann (Barcelona, Spain) from 2007 to 2020. For this study, the patient cohort consisted of 240 patients of the Catalonia region of Spain (Table 2). In the cohort there are twice as many male patients as female patients; there was no way to control for this gender ratio in the admitted patients or any gender bias in the referral from acute treatment units. Inclusion criteria for this cohort consisted of adult patients 18 to 85 years of age at the time of stroke with an ischemic stroke diagnosis who were admitted within 3 weeks of the onset of symptoms, without any previous comorbidities leading to disability, and whose data was recorded within a week of admission and discharge. Exclusion criteria were any of the following: diagnosis of stroke in the context of another concomitant comorbidity (e.g., traumatic brain injury), a previous history of another disabling condition, patients with EVSF assessment performed more than 5 months post injury, as well as more than 5 months stay at the rehabilitation hospital. 


\section{TABLE 1 EVSF assessment items and risk scoring metric}

\begin{tabular}{llr} 
Items & Level of risks & Score \\
\hline Cohabitation & & 1 \\
& Lives with family/core of coexistence or stable partner & 2 \\
& Lives in a residence in stable situation & 3 \\
& Lives alone, but with a close family circle (children, siblings) \\
& Lives with non-relatives or with person with disability or chronic & 4 \\
& $\quad$ disease & 5 \\
& Lives alone, no relatives close & 1 \\
Economic status & & 2 \\
& & With sufficient and stable incomes \\
& With stable but insufficient incomes & 3 \\
& With minimum incomes (non-contributory benefit) & 4 \\
& With fix incomes received in non-regular basis & 5
\end{tabular}

Home status

Appropriate to your needs

Architectural barriers with possibilities for adaptation 2

Architectural barriers without possibility of adaptation 3

Cannot return home 4

No home 5

Family support

Autonomous/no support needed from family/core of coexistence 1

Family/core of coexistence is able to provide the required support 2

Family/core of coexistence \& limited capacity of providing support 3

Rejected or abandoned by family or by core of coexistence 4

No family/ No core of coexistence 5

\section{Social support}

Autonomous or with enough informal support $\quad 1$

Not enough social support, but can afford private services 2

Not enough social support, needs proximity public services (e.g., 3 home health care, day centre)

Needs public institutional alternative (e.g., long term sociosanitary 4 centre or assisted residence)

Cannot access to public support (e.g., foreigner without residence 5 card) 


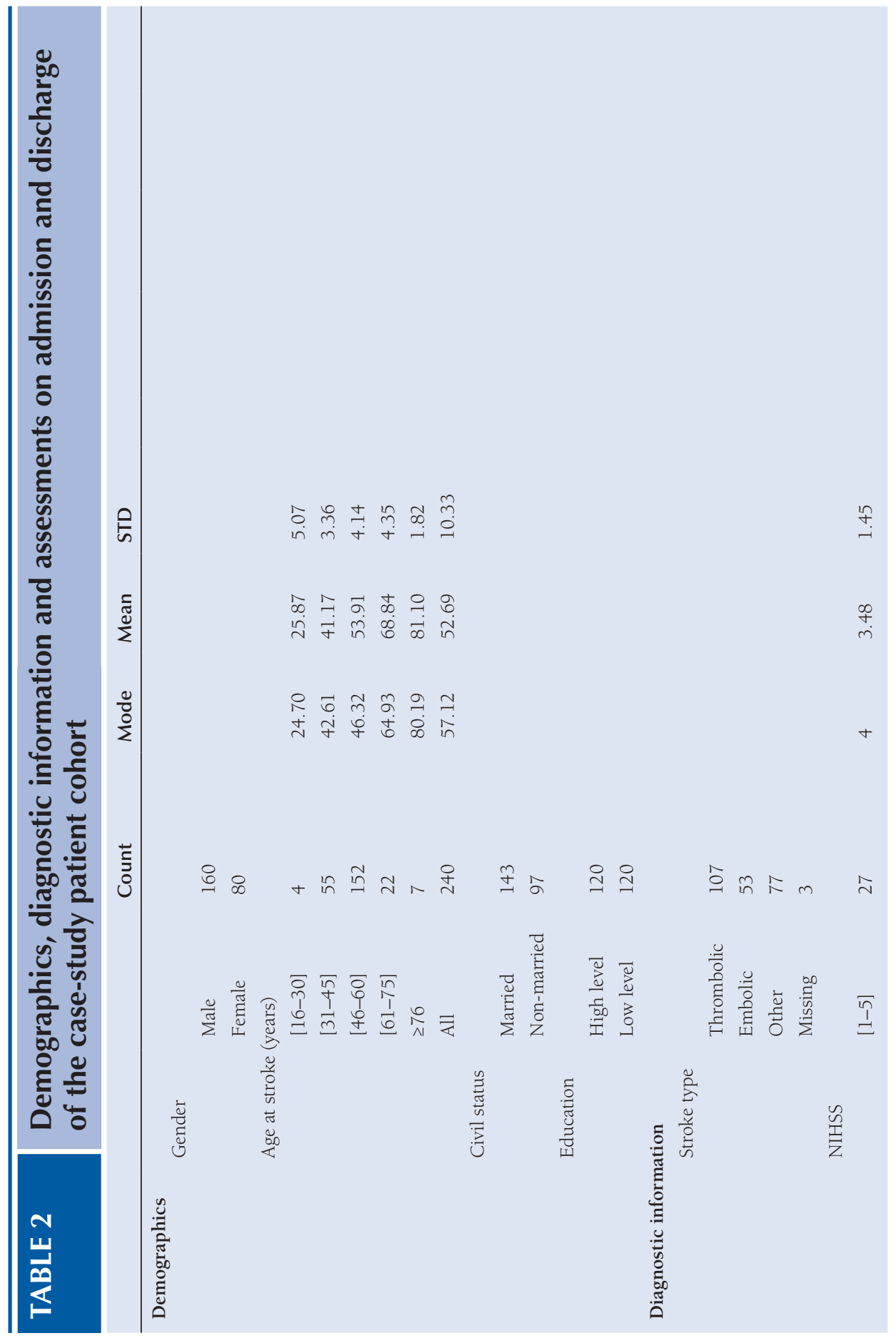




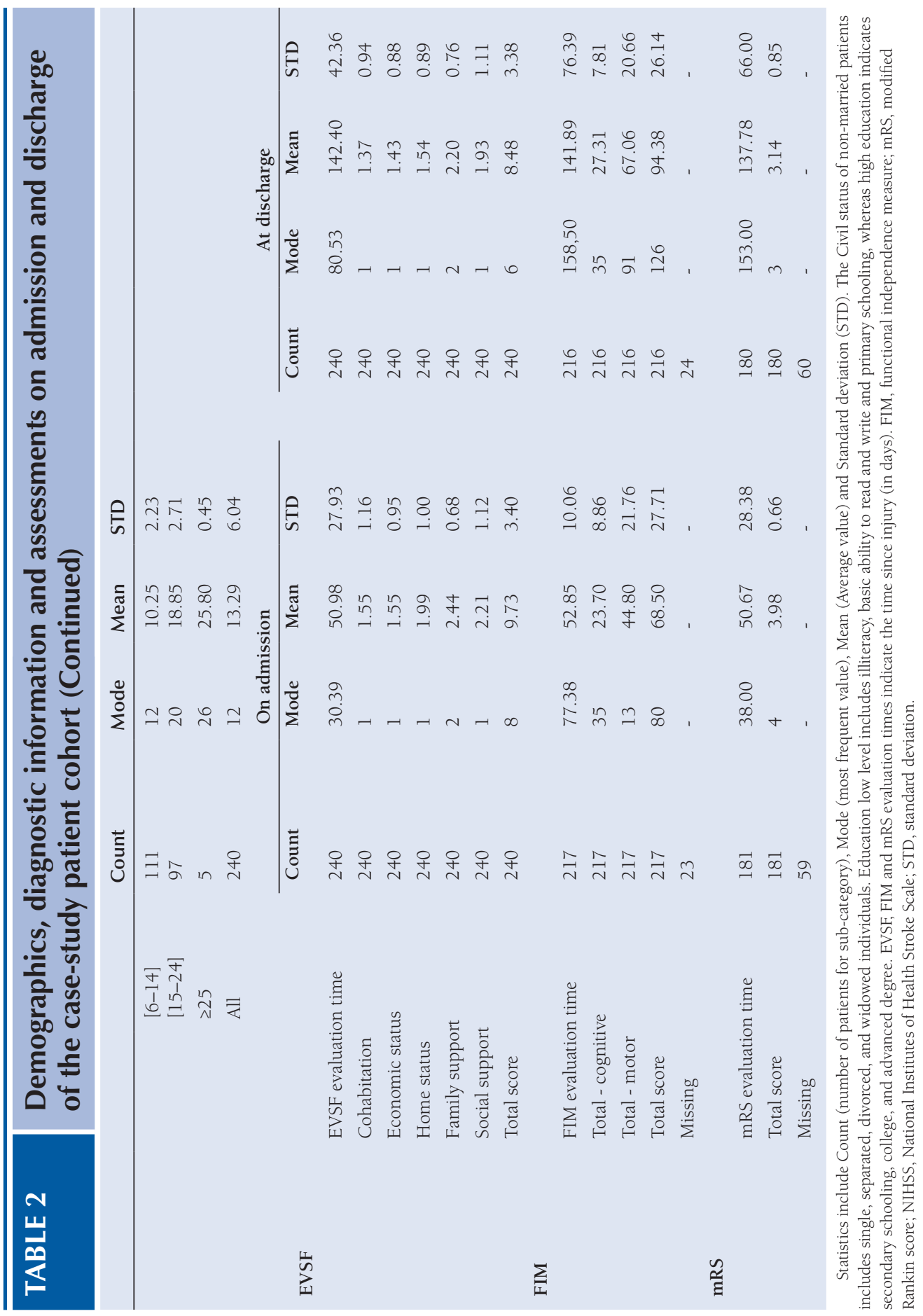




\section{Sankey visualizations of risk variation}

Clinical data visualization that enables straightforward interpretation and evaluation of information is a hot topic in medicine, owing to the growing volume of clinical data $(41,42)$. Moreover, the visualization of patient health information, various assessments and questionnaires has been successfully implemented using Sankey diagrams, which graphically display the flow between successive steps (such as admission and discharge from hospital) with ribbons whose thickness is proportional to quantity (43). Therefore, Sankey diagrams were utilized in this case study in order to visually evaluate which EVSF dimensions contribute to increased social risk (important and severe social risk categories), as well as which dimensions contribute to patient improvement or increase of social risk at discharge.

\section{Social risk categories and risk factors}

For the 240-patient population cohort in this case study and four social risk categories of the EVSF questionnaire (Figure 1), most individuals fall in the mild and important risk categories both from admission to discharge (Figure 1A). On the basis of available demographic, diagnostic and assessment data available, eight factors were selected for Sankey visualizations (Figure 1B-I) with variable cohort distributions: gender, education, functional independence measure-motor (FIM-motor) assessment, modified Rankin score (mRS) assessment, age, civil status, NIHSS, and length of stay (LOS) at the hospital. The gender factor subdivided the cohort into male and female patients, education into high level (secondary schooling, college, and advanced degree) and low education (illiteracy, basic reading and writing, and primary schooling), the FIM-motor assessment into poor FIM-motor score $<65$ and good FIM-motor score $\geq 65$ (44), good mRS outcome $0-2$ and poor mRS outcome 3-6 (45), age $<55$ and $\geq 55$ years old (46), civil status into married and non-married (including single, separated, divorced and widowed), mild stroke NIHSS $<15$ and severe stroke NIHSS $\geq 15$ (47) and length of stay $($ LOS) $<90$ days and $\geq 90$ days.

When considering these social risk factors, certain trends are not surprising, for example, that married (Figure 1E) or younger (Figure 1D) patients or patients with higher level of education (Figure 1C) or a milder stroke (Figure $1 \mathrm{G}$ ) or without significant disability (Figure $1 \mathrm{H}$ ) are mainly in the mild or no social risk categories upon discharge from the hospital. However, what may be unexpected is that non-married, older patients, patients with a lower level of education, patients with severe stroke, and patients with significant disability also follow the same trend of the mild or no social risk categories upon discharge from the hospital. This is likely due to the complex and multifactorial nature of social risk (5), where a combination, rather than a single risk factor may be increasing social risk for individuals. This may also be the case for gender (Figure 1B), where considering gender bias and the difficulties female patients may encounter during acute treatment (7), one may expect a reverse trend for male and female patients, with more women rather than men in important and severe risk categories upon discharge from the rehabilitation hospital. 

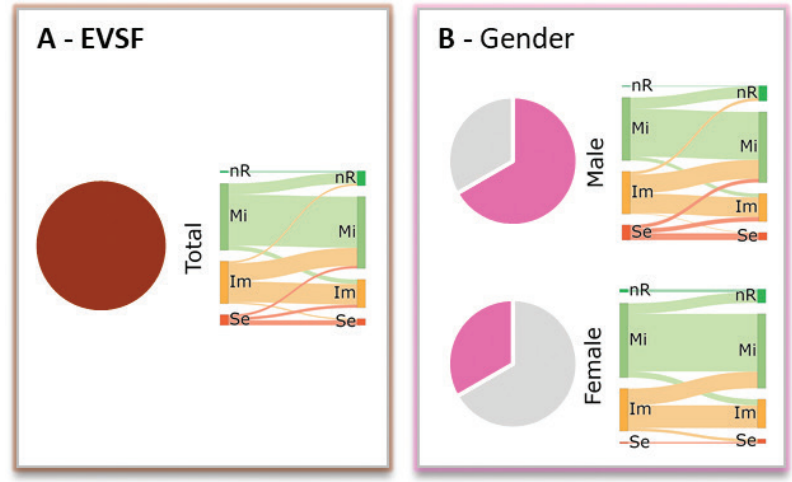

$$
\text { D - Age }
$$

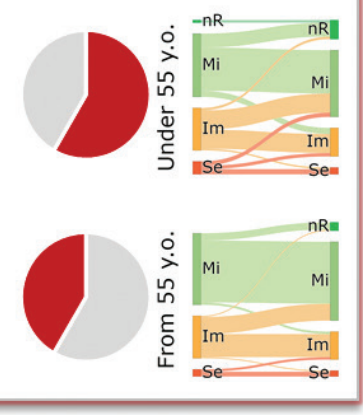

\section{G - NIHSS}

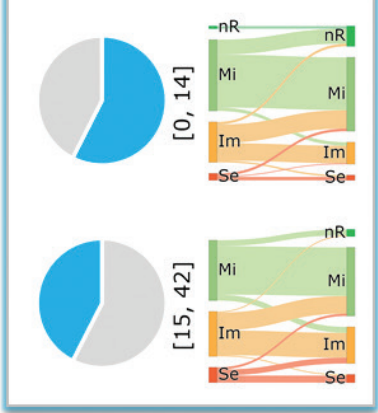

\section{C - Education}

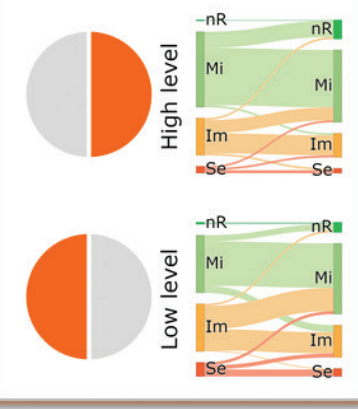

\section{E - Civil Status}

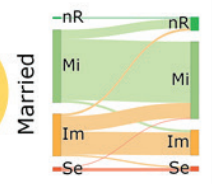

\section{F - FIM Motor}
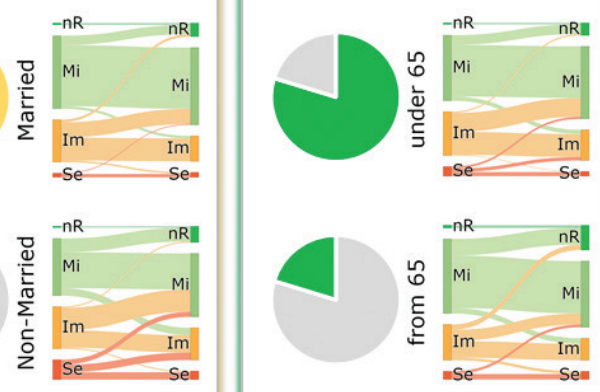

I - LOS

H - mRS
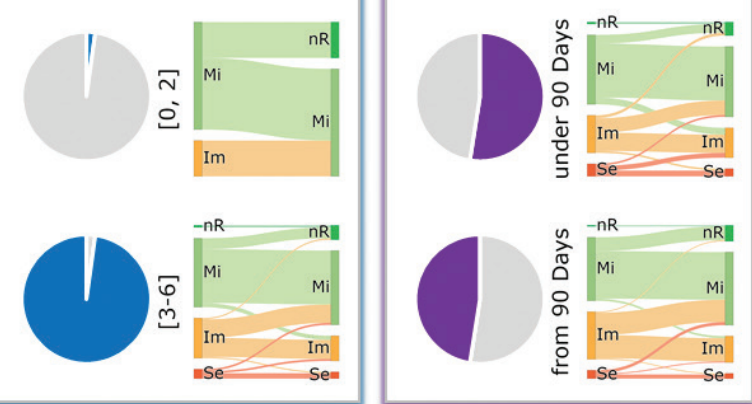

Figure 1 Patient EVSF social risk variation from admission to discharge across four categories: no risk (nR), mild risk (Mi), important risk (Im) and severe risk (Se). A, EVSF risk variation of the studied cohort. B-I, EVSF risk variations of eight factors: gender, education, age, civil status, FIM-motor assessment, NIHSS, mRS assessment, and length of stay (LOS) at the hospital, respectively, with their corresponding cohort distributions. 


\section{Improvement of social risk categories}

In order to evaluate social risk, each of the 240 patients EVSF social risk categories at admission were compared to their categories at discharge (Figure 1A). If a patient remained in the same social risk category (e.g., mild risk category at admission and mild risk category at discharge, or, severe risk at admission and severe risk at discharge), their improvement level was 0 ; if the patient improved their social risk (e.g., transitioning one risk category only: from mild risk to no risk, or from important risk to mild risk), then their improvement was +1 ; alternatively if a patient increased their social risk (e.g., transitioning one category only: from no risk to mild risk, or mild risk to important risk) their improvement level was -1. In a few instances, patients greatly improved their social risk, transitioning from severe social risk to mild risk or important social risk to no risk (e.g., transitioning two categories) hence their improvement level was +2 . There were no instances of patients increasing their social risk drastically (e.g., decline by two categories), therefore, there was no improvement level -2. In the Sankey visualization (Figure 2) of the 240-patient population cohort, the social risk improvement distribution is as follows: (i) (+2) -9 patients; (ii) (+1) -64 patients; (iii) (0) -155 patients; (iv) (-1) -12 patients.

Although the overall cohabitation dimension (Figure 2A) scores are mainly low social risk (green), for the improvement level +2 (Figure 2B), this dimension, as well as family support, greatly contribute to the decrease in social risk (red); indeed, in this improvement level, there are no patients in important or severe risk category at discharge (all scores across dimensions are $\leq 3$ ). For the improvement level +1 , although some patients were still living alone without relatives at discharge (cohabitation score 5; red) this dimension and the social support dimension greatly contributed to improved social risk at discharge (green). In parallel, for the improvement level -1 (Figure 2B), these same dimensions of cohabitation and social support display an increase in social risk from admission (green) to discharge (orange). Because most patients stay in the same risk category, improvement level 0 was subsequently subdivided into patients belonging to the no risk or mild risk categories, and important and severe risk categories (Figure 2C). As expected, patients in the low-risk categories are in a stable social situation at discharge, with the majority of patients relying on family for support (EVSF score 2; sage-green). However, patients in the high-risk categories would benefit from personalized interventions across all five dimensions, especially family and social support. The Sankey visualizations can aid in ranking of the EVSF dimensions according to each dimension's possible contribution to overall social risk for the population; for the case study cohort, dimensions contributing to social risk were primarily family support, followed by social support, home status, cohabitation and the least by economic status.

\section{Gender impact on social risk}

As gender plays an important role in social risk (48), the case study explores risk variation and improvement between male and female patients (Figure 3). In the 
A
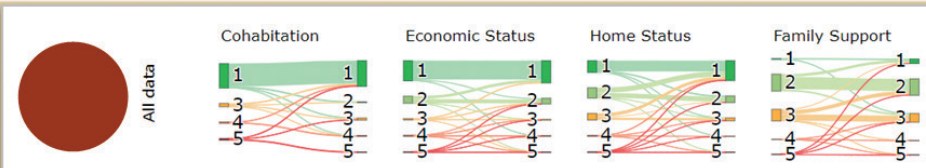

Social Support

a1 1 .

$\begin{array}{ll}-2 & 2\end{array}$

$-3$ $\begin{array}{ll}-4 & 3 \\ -5 & 4-\end{array}$
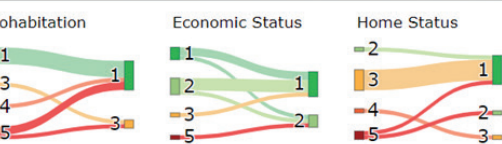

Family Support

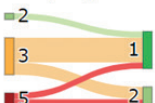

Social Support

$\square 2$
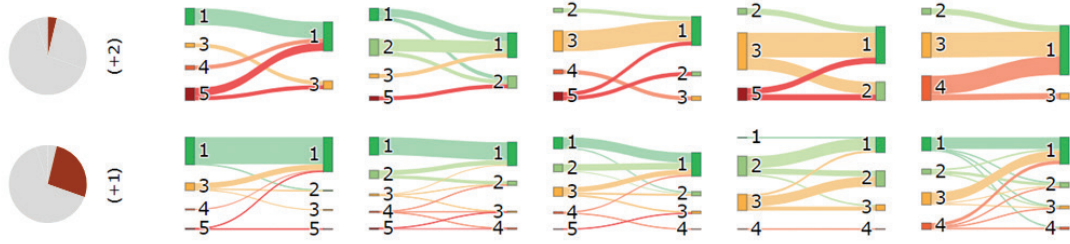

B
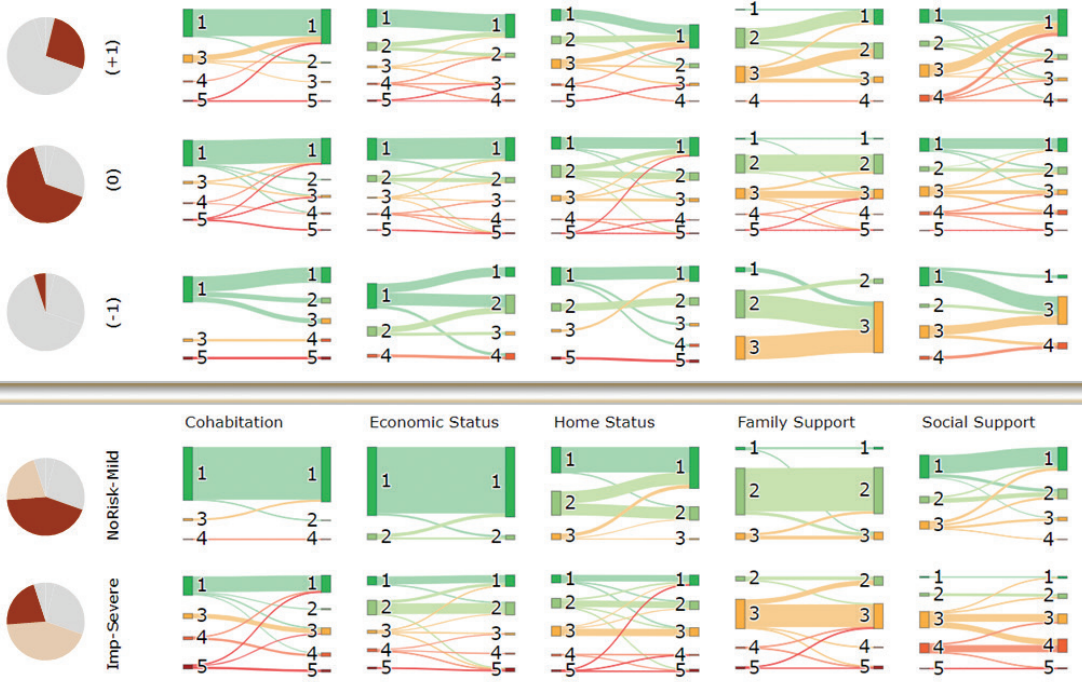

Figure 2 Patient social risk improvement levels from admission to discharge across the EVSF dimensions. The Sankey node colors indicate EVSF item score: 1 (green), 2 (sage-green), 3 (orange), 4 (dark orange) and 5 (red). A, Risk scoring variation at each EVSF items visualized from the studied cohort. B, Risk scoring variation at four improvement levels of social risk categories across each EVSF item. The patient distribution: (+2) 9 patients; (+1) 64 patients; (0) 155 patients and (-1) 12 patients. C, Breakdown of risk scoring variation at the improvement level $(0)$ of two social risk categories, (i) no risk and mild: 104 patients and (ii) important and severe: 51 patients, across each EVSF item.

cohort, male patients outnumber female patients 2:1, where 160 are men and 80 are women (Figure 3A, C). The Sankey representations show that women are in a much better situation at admission for most dimensions, i.e., there are proportionally fewer women at high social risk (red) than men (Figure 3B, D), and accordingly, there is no improvement level +2 for women (Figure 3D). For both men and women, home status and social support dimensions improve the most, and also for men, cohabitation social risk improves from admission to discharge, especially for improvement level +2 (Figure 3B). Conversely, for the increased 


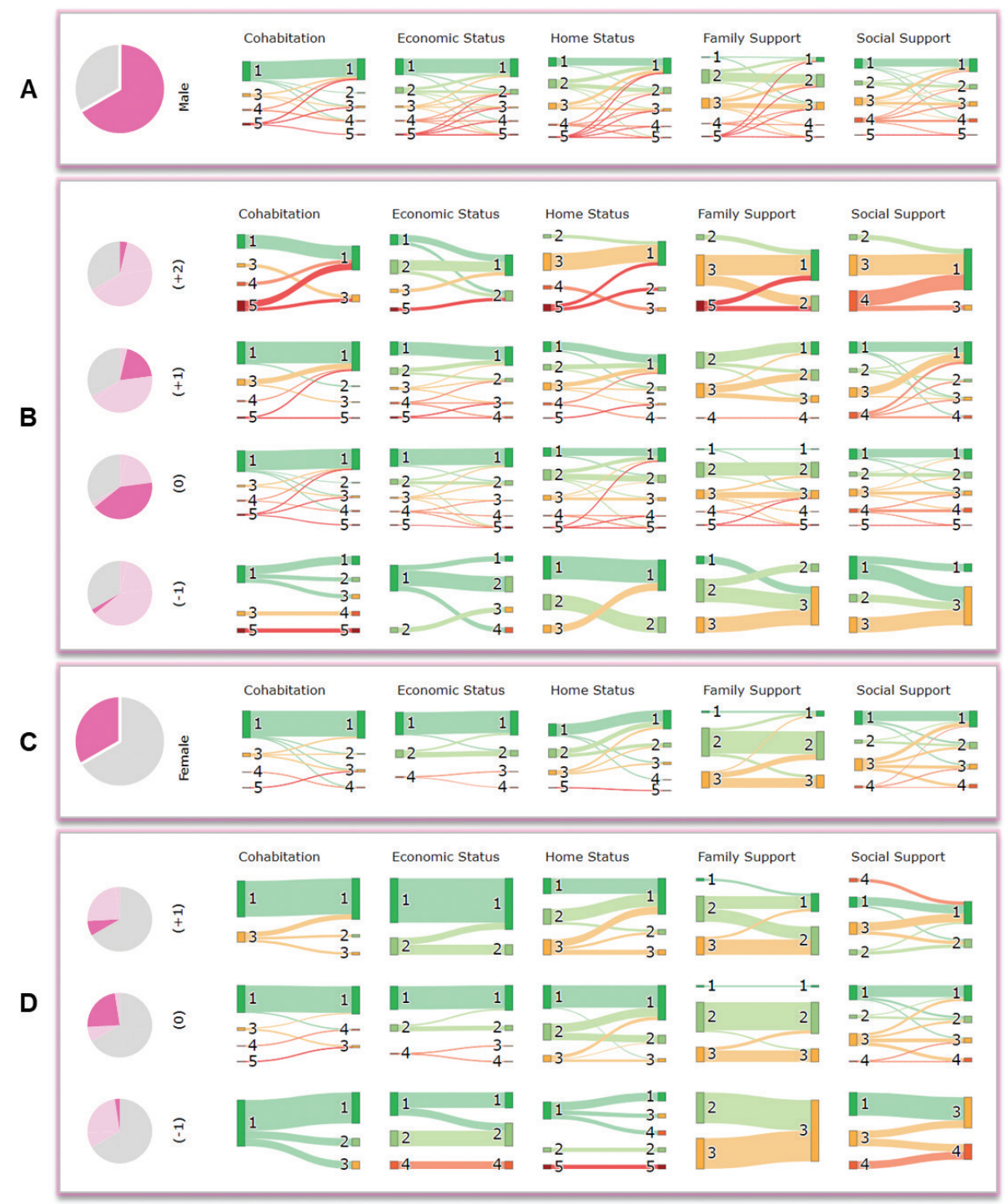

Figure 3 Patient social risk improvement levels for men (AB) and women (CD) from admission to discharge across the EVSF dimensions. The Sankey node colors indicate EVSF item score:

1 (green), 2 (sage-green), 3 (orange), 4 (dark orange) and 5 (red). A, Risk scoring variation at each EVSF items for all male patients in the studied cohort (160 patients). B, Breakdown of risk scoring variation at four improvement levels of social risk categories across each EVSF item of male patients. The patient distribution: (+2) 9 patients; (+1) 46 patients; (0) 99 patients and (-1) 6 patients. C, Risk scoring variation at each EVSF items for all female patients in the studied cohort (80 patients). D, Breakdown of risk scoring variation at three improvement levels of social risk categories across each EVSF item of female patients. The patient distribution: (+1) 18 patients; (0) 56 patients and (-1) 6 patients. 
A

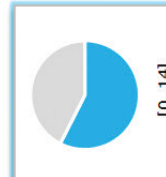

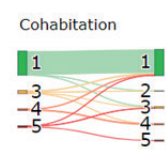
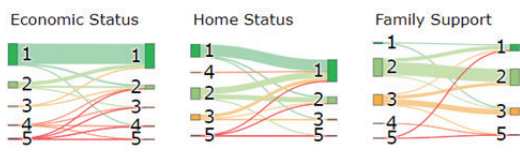

Social Support

11

$-2 \quad 2=$
-3

$\begin{array}{ll}3 & 3= \\ -4 & 4-\end{array}$

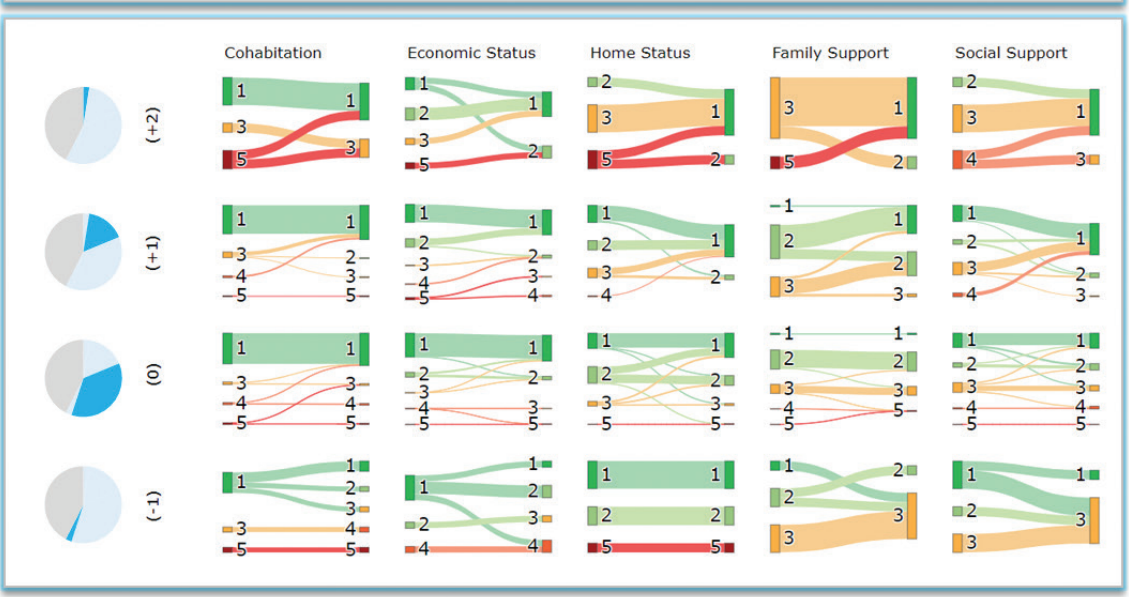

B

C
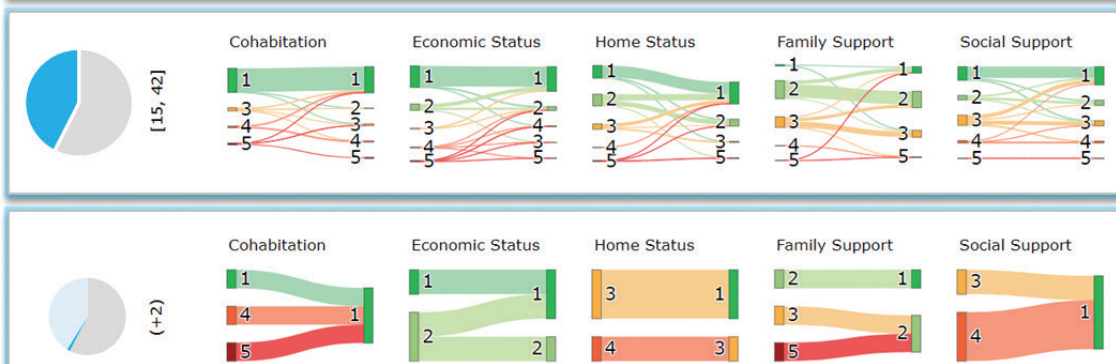

Economic Status

Home Status

Family Support
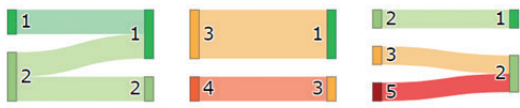

Social Support
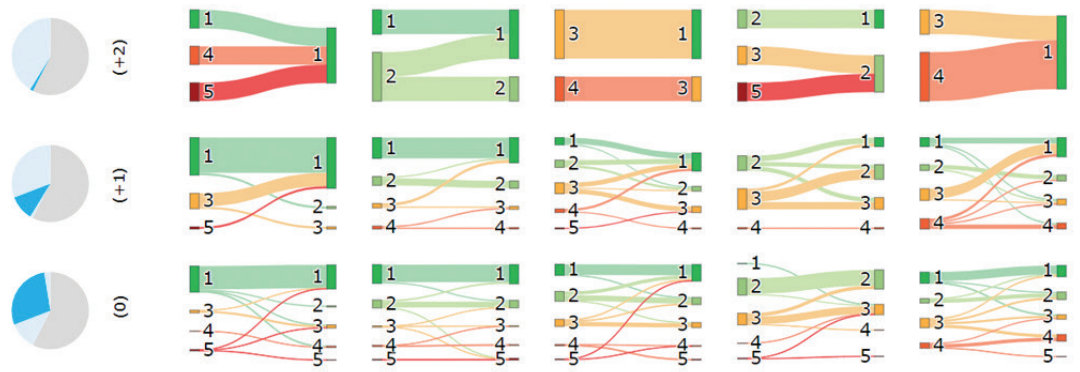

$-4 \quad 4-$
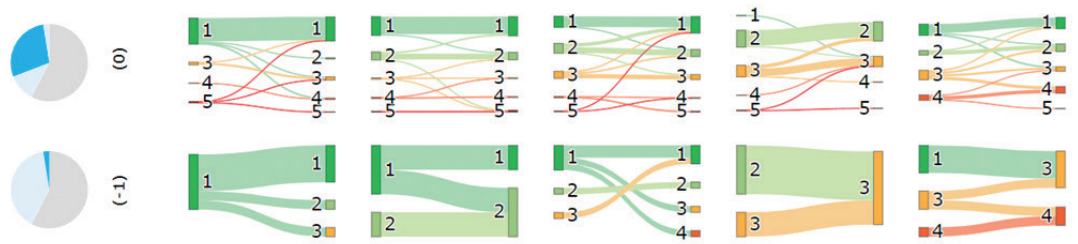

Figure 4 Patient social risk improvement levels for mild (AB) and severe (CD) stroke from

admission to discharge across the EVSF dimensions. The Sankey node colors indicate EVSF item score: 1 (green), 2 (sage-green), 3 (orange), 4 (dark orange) and 5 (red). A, Risk scoring variation at each EVSF items for mild stroke patients (NIHSS $<15$ ) in the studied cohort (138 patients).

B, Breakdown of risk scoring variation at four improvement levels of social risk categories across each EVSF item of mild stroke patients. The patient distribution: (+2) 6 patients; (+1) 39 patients; (0) 87 patients and $(-1) 6$ patients. C, Risk scoring variation at each EVSF items for severe stroke patients (NIHSS $\geq 15$ ) in the studied cohort (102 patients). D, Breakdown of risk scoring variation at four improvement levels of social risk categories across each EVSF item of severe stroke patients. The patient distribution: (+2) 3 patients; (+1) 25 patients; (0) 68 patients and $(-1) 6$ patients. 
social risk in men in improvement level -1, cohabitation situation worsens as more patients are mainly living alone (red), whereas for women at this improvement level (Figure 3D), it is the home status (red), as more women do not have a home to return to, as well as needing to live in a care home at discharge. For the case study cohort and female patients, the EVSF dimensions contributing to social risk were primarily home status, social support, followed by economic status, cohabitation and the least by family support; whereas for the male patients: social support, followed by cohabitation, family support, economic status, and the least by home status.

\section{Stroke severity impact on social risk}

An association between social risk, the socioeconomic situation and stroke severity as assessed by the NIHSS has not been fully elucidated $(49,50)$. In this case study, risk variation was explored for patients with mild stroke (NIHSS $<15$ ) and severe stroke (NIHSS $\geq 15$ ) (Figure 4A, C) (47). For the few patients with mild stroke (Figure 4B), home status, family and social support dimensions show the most social risk decrease on discharge (green) in improvement level +2 , whereas for patients with severe stroke, cohabitation and social support show the most social risk decrease on discharge (green) in the improvement level +2 . For the improvement level +1 , both mild and severe stroke patient populations (Figure 4B, D) have similar trends, with the mild stroke patient population decreasing social risk in the family support dimension, but severe stroke patient population in the cohabitation dimension. Conversely, for the improvement level -1 , the severe stroke patient population increases social risk in the cohabitation dimension, whereas the mild stroke patient population increases risk in the family and social support dimensions. As in the overall patient cohort, the improvement level 0 (no improvement) is the most common for both the mild and severe stroke patient population, indicating that most patients stay in the same social risk category from admission to discharge, and showing similar trends across all dimensions from admission to discharge. For the case study cohort and mild stroke patients, the EVSF dimensions contributing to social risk were primarily home status, family support, followed by cohabitation, economic status and the least by social support; whereas for the severe stroke patients: social support, followed by cohabitation, home status, family support and the least by economic status.

\section{CONCLUSION}

Social risk plays an important role in the quality of life of post-ischemic stroke patients during reintegration. Due to the complexity of reintegration, encompassing the spatiotemporal component (long term process taking place in the home, community, and workplace), multifactorial component (interdependency of psychosocial, environmental, and socio-economic factors) as well as demographic and cultural factors (gender, geographic location), visualization of patient data is an invaluable tool for interpretation of patient trajectories and social risk status. For the case study 240-patient cohort of the Catalonia region of Spain, consisting of mostly male, young ischemic stroke patients, although most individuals were 
mainly in the mild or no social risk categories upon discharge from the hospital, exploration of social risk improvement levels revealed that dimensions contributing to social risk were primarily family support, followed by social support, home status, cohabitation and the least by economic status, but rank order of dimensions varied when considering social risk factors such as gender and stroke severity.

Acknowledgment: This research was supported by the PRECISE4Q project, funded through the European Union's Horizon 2020 research and innovation program under grant agreement No. 777107, and the ADAPT Research Centre, funded by Science Foundation Ireland (Grant 13/RC/2106_P2) and is co-funded by the European Regional Development fund.

Conflict of Interest: The authors declare no potential conflicts of interest with respect to research, authorship and/or publication of this manuscript.

Copyright and Permission Statement: The authors confirm that the materials included in this chapter do not violate copyright laws. Where relevant, appropriate permissions have been obtained from the original copyright holder(s), and all original sources have been appropriately acknowledged or referenced.

\section{REFERENCES}

1. Boot E, Ekker MS, Putaala J, Kittner S, De Leeuw F-E, Tuladhar AM. Ischaemic stroke in young adults: a global perspective. J Neurol Neurosurg Psychiatry. 2020;91(4):411-7. https://doi.org/10.1136/ jnnp-2019-322424

2. Ramirez L, Kim-Tenser MA, Sanossian N, Cen S, Wen G, He S, et al. Trends in Acute Ischemic Stroke Hospitalizations in the United States. J Am Heart Assoc [Internet]. 2016;5(5). Available from: https:// doi.org/10.1161/JAHA.116.003233

3. Tibæk M, Dehlendorff C, Jørgensen HS, Forchhammer HB, Johnsen SP, Kammersgaard LP. Increasing Incidence of Hospitalization for Stroke and Transient Ischemic Attack in Young Adults: A RegistryBased Study. J Am Heart Assoc. 2016;5(5). https://doi.org/10.1161/JAHA.115.003158

4. Lutski M, Zucker I, Shohat T, Tanne D. Characteristics and Outcomes of Young Patients with FirstEver Ischemic Stroke Compared to Older Patients: The National Acute Stroke Israeli Registry. Front Neurol. 2017;8:421. https://doi.org/10.3389/fneur.2017.00421

5. Walsh ME, Galvin R, Loughnane C, Macey C, Horgan NF. Factors associated with community reintegration in the first year after stroke: a qualitative meta-synthesis. Vol. 37, Disability and Rehabilitation. 2015. p. 1599-608. https://doi.org/10.3109/09638288.2014.974834

6. Reeves MJ, Bushnell CD, Howard G, Gargano JW, Duncan PW, Lynch G, et al. Sex differences in stroke: epidemiology, clinical presentation, medical care, and outcomes. Lancet Neurol. 2008;7(10):915-26. https://doi.org/10.1016/S1474-4422(08)70193-5

7. Di Carlo A, Lamassa M, Baldereschi M, Pracucci G, Basile AM, Wolfe CDA, et al. Sex Differences in the Clinical Presentation, Resource Use, and 3-Month Outcome of Acute Stroke in Europe: Data From a Multicenter Multinational Hospital-Based Registry. Stroke. 2003;34(5):1114-9. https://doi. org/10.1161/01.STR.0000068410.07397.D7

8. Fredwall M, Sternberg S, Blackhurst D, Lee A, Leacock R, Nathaniel TI. Gender Differences in Exclusion Criteria for Recombinant Tissue-Type Plasminogen Activator. J Stroke Cerebrovasc Dis. 2016;25(11):2569-74. https://doi.org/10.1016/j.jstrokecerebrovasdis.2016.06.012 
9. The GBD 2016 Lifetime Risk of Stroke Collaborators. Global, Regional, and Country-Specific Lifetime Risks of Stroke, 1990 and 2016. N Engl J Med. 2018;379(25):2429-37. https://doi.org/10.1056/ NEJMoal 804492

10. Maaijwee NAMM, Rutten-Jacobs LCA, Schaapsmeerders P, van Dijk EJ, de Leeuw F-E. Ischaemic stroke in young adults: risk factors and long-term consequences. Nat Rev Neurol. 2014;10(6): 315-25. https://doi.org/10.1038/nrneurol.2014.72

11. Donkor ES. Stroke in the $21 \mathrm{~s} \mathrm{t}$ Century: A Snapshot of the Burden, Epidemiology, and Quality of Life. Stroke Res Treat. 2018;2018:1-10. https://doi.org/10.1155/2018/3238165

12. Shavelle RM, Brooks JC, Strauss DJ, Turner-Stokes L. Life Expectancy after Stroke Based On Age, Sex, and Rankin Grade of Disability: A Synthesis. J Stroke Cerebrovasc Dis. 2019;28(12):104450. https:// doi.org/10.1016/j.jstrokecerebrovasdis.2019.104450

13. Stack CA, Cole JW. Ischemic stroke in young adults. Curr Opin Cardiol. 2018;33(6):594-604. https:// doi.org/10.1097/HCO.0000000000000564

14. Marcheschi E, Von Koch L, Pessah-Rasmussen H, Elf M. Home setting after stroke, facilitators and barriers: A systematic literature review. Health Soc Care Community. 2018;26(4):e451-9. https://doi. org/10.1111/hsc. 12518

15. Zawawi NSM, Aziz NA, Fisher R, Ahmad K, Walker MF. The Unmet Needs of Stroke Survivors and Stroke Caregivers: A Systematic Narrative Review. Vol. 29, J Stroke Cerebrovasc Dis 2020. https://doi. org/10.1016/j.jstrokecerebrovasdis.2020.104875

16. Trigg R, Wood VA, Hewer RL. Social reintegration after stroke: the first stages in the development of the Subjective Index of Physical and Social Outcome (SIPSO). Clin Rehabil. 1999;13(4):341-53. https://doi.org/10.1191/026921599676390259

17. Wood-Dauphinee SL, Opzoomer MA, Williams JI, Marchand B, Spitzer WO. Assessment of global function: The Reintegration to Normal Living Index. Arch Phys Med Rehabil. 1988;69(8):583-90.

18. Sarre S, Redlich C, Tinker A, Sadler E, Bhalla A, McKevitt C. A systematic review of qualitative studies on adjusting after stroke: lessons for the study of resilience. Disabil Rehabil. 2014;36(9):716-26. https://doi.org/10.3109/09638288.2013.814724

19. Garcia-Rudolph A, Saurí J, Cegarra B, Bernabeu Guitart M. Discovering the Context of People With Disabilities: Semantic Categorization Test and Environmental Factors Mapping of Word Embeddings from Reddit. JMIR Med Inform. 2020;8(11):e17903. https://doi.org/10.2196/17903

20. Silva RA, Martins AKL, de Castro NB, Viana AV, Butcher, HK, da Siva VM. Analysis of the concept of powerlessness in individuals with stroke. Investig Educ En Enferm. 2017;35(3):306-19. https://doi. org/10.17533/udea.iee.v35n3a07

21. Elloker T, Rhoda A, Arowoiya A, Lawal IU. Factors predicting community participation in patients living with stroke, in the Western Cape, South Africa. Vol. 41, Disabil Rehabil. 2019. p. 2640-7. https:// doi.org/10.1080/09638288.2018.1473509

22. Teoh V, Sims J, Milgrom J. Psychosocial Predictors of Quality of Life in a Sample of CommunityDwelling Stroke Survivors: A Longitudinal Study. Vol. 16, Top Stroke Rehabil. 2009. p. 157-66. https://doi.org/10.1310/tsr1602-157

23. White J, Magin P, Attia J, Sturm J, McElduff P, Carter G. Predictors of health-related quality of life in community-dwelling stroke survivors: a cohort study. Vol. 33, Fam Pract. 2016. p. 382-7. https://doi. org/10.1093/fampra/cmw011

24. Mackenzie A, Chang A. Predictors of quality of life following stroke. Vol. 24, Disabil Rehabil. 2002. p. 259-65. https://doi.org/10.1080/09638380110081805

25. Hines A, Kelleher JD. A framework for post-stroke quality of life prediction using structured prediction. In: 2017 Ninth International Conference on Quality of Multimedia Experience (QoMEX). Erfurt, Germany: IEEE; 2017 p. 1-6. https://doi.org/10.1109/QoMEX.2017.7965672

26. Yasui NY, Berven NL. Community integration: conceptualisation and measurement. Vol. 31, Disabil Rehabil.. 2009. p. 761-71. https://doi.org/10.1080/09638280802306638

27. Dijkers M. Community Integration Questionnaire. In: Kreutzer JS, DeLuca J, Caplan B, editors. Encyclopedia of Clinical Neuropsychology. New York, NY: Springer New York; 2011 [cited 2021 Sep 14]. p. 651-4. https://doi.org/10.1007/978-0-387-79948-3_1799 
28. Rabin R, Gudex C, Selai C, Herdman M. From Translation to Version Management: A History and Review of Methods for the Cultural Adaptation of the EuroQol Five-Dimensional Questionnaire. Value Health. 2014;17(1):70-6. https://doi.org/10.1016/j.jval.2013.10.006

29. Anderson S, Whitfield K. Social identity and stroke: 'they don't make me feel like, there's something wrong with me'. Scand J Caring Sci. 2013;27:2013. p. 820-30. https://doi.org/10.1111/j. 1471-6712.2012.01086.x

30. Kruithof WJ, van Mierlo ML, Visser-Meily JMA, van Heugten CM, Post MWM. Associations between social support and stroke survivors' health-related quality of life-A systematic review. Vol. 93, Patient Educ Couns. 2013. p. 169-76. https://doi.org/10.1016/j.pec.2013.06.003

31. Grant J, Elliott T, Giger J, Bartolucci A. Social problem-solving abilities, social support, and adjustment among family caregivers of individuals with a stroke. Vol. 46, Rehabil Psychol. 2001. p. 44-57. https://doi.org/10.1037/0090-5550.46.1.44

32. Bilbao A, Kennedy C, Chatterji S, Ustün B, Barquero JLV, Barth JT. The ICF: Applications of the WHO model of functioning, disability and health to brain injury rehabilitation. NeuroRehabilitation. 2003;18(3):239-50. https://doi.org/10.3233/NRE-2003-18308

33. World Health Organization, editor. International classification of functioning, disability and health: ICF. Geneva: World Health Organization; 2001. 299 p.

34. The United Nations. Convention on the Rights of Persons with Disabilities [Internet]. 2006. Available from: https://www.un.org/development/desa/disabilities/convention-on-the-rights-of-persons-withdisabilities.html

35. COCEMFE [Internet]. 2019. Available from: https://www.cocemfe.es/informate/noticias/18-millonesde-personas-con-movilidad-reducida-dependen-de-la-ayuda-de-terceros-para-salir-de-su-casa-y100-000-no-salen-nuncal

36. Kyzar KB, Turnbull AP, Summers JA, Gómez VA. The Relationship of Family Support to Family Outcomes: A Synthesis of Key Findings from Research on Severe Disability. Res Pract Pers Sev Disabil. 2012;37(1):31-44. https://doi.org/10.2511/027494812800903247

37. Berkman LF, Kawachi I, Glymour MM, editors. Social Epidemiology. Oxford University Press; 2014. https://doi.org/10.1093/med/9780195377903.001.0001

38. Holt-Lunstad J, Smith TB, Layton JB. Social Relationships and Mortality Risk: A Meta-analytic Review. Brayne C, editor. PLoS Med. 2010;7(7):e1000316. https://doi.org/10.1371/journal.pmed.1000316

39. Tough H, Siegrist J, Fekete C. Social relationships, mental health and wellbeing in physical disability: a systematic review. BMC Public Health. 2017;17(1):414. https://doi.org/10.1186/s12889-017-4308-6

40. García González JV, Díaz Palacios E, Salamea García A, Cabrera González D, Menéndez Caicoya A, Fernández Sánchez A, et al. [An evaluation of the feasibility and validity of a scale of social assessment of the elderly]. Aten Primaria. 1999;23(7):434-40.

41. Wanderer JP, Nelson SE, Ehrenfeld JM, Monahan S, Park S. Clinical Data Visualization: The Current State and Future Needs. J Med Syst. 2016;40(12):275. https://doi.org/10.1007/s10916-016-0643-x

42. Roham M, Gabrielyan AR, Archer N. A Systematic Review of Knowledge Visualization Approaches Using Big Data Methodology for Clinical Decision Support. In: Sartipi K, Edoh T, editors. Recent Advances in Digital System Diagnosis and Management of Healthcare. IntechOpen; 2021 https://doi. org/10.5772/intechopen.90266

43. Lamer A, Laurent G, Pelayo S, El Amrani M, Chazard E, Marcilly R. Exploring Patient Path Through Sankey Diagram: A Proof of Concept. Stud Health Technol Inform. 2020;270:218-22.

44. Scrutinio D, Battista P, Guida P, Lanzillo B, Tortelli R. Sex Differences in Long-Term Mortality and Functional Outcome After Rehabilitation in Patients With Severe Stroke. Front Neurol. 2020;11:84. https://doi.org/10.3389/fneur.2020.00084

45. Banks JL, Marotta CA. Outcomes Validity and Reliability of the Modified Rankin Scale: Implications for Stroke Clinical Trials: A Literature Review and Synthesis. Stroke. 2007;38(3):1091-6. https://doi. org/10.1161/01.STR.0000258355.23810.c6

46. Black-Schaffer RM, Winston C. Age and Functional Outcome After Stroke. Top Stroke Rehabil. 2004;11(2):23-32. https://doi.org/10.1310/DNJU-9VUH-BXU2-DJYU 
47. Brott T, Adams HP, Olinger CP, Marler JR, Barsan WG, Biller J, et al. Measurements of acute cerebral infarction: a clinical examination scale. Stroke. 1989;20(7):864-70. https://doi.org/10.1161/01. STR.20.7.864

48. Momtaz Y, Delbari A, Keyghobadi F, Keyghobadi F, Akbari R, Kamranian H, et al. Sex differences in stroke: a socioeconomic perspective. Clin Interv Aging. 2016;11:1207-12. https://doi.org/10.2147/ CIA.S113302

49. Kerr GD, Higgins P, Walters M, Ghosh SK, Wright F, Langhorne P, et al. Socioeconomic Status and Transient Ischaemic Attack/Stroke: A Prospective Observational Study. Cerebrovasc Dis. 2011;31(2):130-7. https://doi.org/10.1159/000321732

50. Arrich J, Müllner M, Lalouschek W, Greisenegger S, Crevenna R, Herkner H. Influence of Socioeconomic Status and Gender on Stroke Treatment and Diagnostics. Stroke. 2008;39(7): 2066-72. https://doi.org/10.1161/STROKEAHA.107.506147 
